\title{
ACCURACY ANALYSIS OF SENTINEL 2A AND LANDSAT 8 OLI+ SATELLITE DATASETS OVER KANO STATE (NIGERIA) USING VEGETATION SPECTRAL INDICES
}

\author{
O. A. Isioye ${ }^{1 *}$, E. A. Akomolafe ${ }^{1}$, U. H. Ikwueze ${ }^{1}$ \\ ${ }^{1}$ Department of Geomatics, Faculty of Environmental Design, Ahmadu Bello University, Samaru, Zaria-Nigeria - \\ lekkyside4u@yahoo.com; goldera2787@gmail.com ; jerryuc2@gmail.com \\ Commission IV
}

KEY WORDS: Sentinel-2A, Landsat-8, NDVI, GCI, MSI, LAI, Spectral Indices

\begin{abstract}
:
This study explores the capabilities of Sentinel-2 over Landsat-8 Operational Land Imager (OLI) imageries for vegetation monitoring in the vegetated region of Minjibir LGA in Kano State. Accurate vegetation mapping is essential for monitoring crop and sustainable agricultural practice. Vegetation indices, comprising the Normalized Difference Vegetation Index (NDVI), Green Chlorophyll Index (GCI), Leaf Area Index (LAI) and Moisture Stress Index (MSI) were determined for each year. The findings showed an increase in Sentinel 2A value of the vegetation indices with respect to Landsat 8 throughout the time of the study (2015-2019). The best average performance over the supervised classification was obtained using Sentinel-2A bands, which are dependent on the training sample and resolution. While the spectral consistency of the data was inferred by cross-calibration analysis using regression analysis. The spatial consistency was assessed by descriptive statistical analysis of examined variables. Regarding the spatial consistency, the mean and standard deviation values of all variables were steady for all seasons excluding for the mean value of the LAI and MSI. Based on this finding, it is recommended that Sentinel-2A data could be used as a complementary data source with Landsat 8 OLI in vegetation assessment.
\end{abstract}

\section{INTRODUCTION}

\subsection{General Instructions}

Land-use mapping is a vital topic in the study of surface ecophysics, together with vegetation, soil, buildings, water, and other surface elements. Amongst them, vegetation is the most subtle to identifying surface climate change (Yuanhuizi et. al 2019). Additionally, vegetation is most closely associated with global and regional food security, planting intensity, crop yields, and other sustainable development goals. Future global climate change has increased the likelihood of severe, pervasive, and irreversible costs for human civilization and agriculture (IPCC, 2014). In the same perspective, the rapid and accurate mapping of vegetation has gradually become a crucial means for monitoring and evaluating agricultural development, and disaster monitoring/ management.

Presently, remote sensing is an applied approach for vegetation appraisal by using vegetation variables, which varies vigorously in time and space (Yuanhuizi et.al 2019). The foremost role of environmental remote sensing to land resource management is its prospect to map vegetation resources and to observe changes that arise over prolonged epochs. Numerous satellite missions are launched with the most objective of observing changes within the vegetative cover over the world surface.

Most of such remote satellite missions are concerned with retrieving explicit vegetation parameters like the Normalized Vegetation Index (NDVI), the Fractional Vegetation Cover (FVC), Leaf Area Index (LAI), Green Chlorophyll Index (GCL), Soil Adjusted Vegetative Index (SAVI), Enhanced Vegetative Index (EVI), etc. (Melaas et al., 2013). Vegetation monitoring remains a fundamental focus within the science and practices of the remote sensing technology. However, the choice or accuracy of remote sensors used in vegetative monitoring remains of great importance. This study explores the Spatiotemporal changes between two remote sensing missions (Landsat 8 Operational Land Imager (OLI) and Sentinel 2A) and their spectral relationship in the region covering Minjibir Local Government Area (LGA) in the Kano State of Nigeria. This is with the objective of analysing the proficiencies of Sentinel-2 data over Landsat-8 OLI data for vegetation planning and monitoring. Four (4) Vegetation indices namely the NDVI, GCI, LAI, and MSI were determined for the period of 20152019.

\subsection{Study Area}

The study area is Minjibir LGA in Kano State. Minjibir lies between geographic latitude $12^{\circ} 00^{\prime} 0^{\prime \prime}$ and $12^{\circ} 20^{\prime} 0^{\prime \prime}$, and longitude $8^{\circ} 30^{\prime} 00^{\prime \prime}$ and $8^{\circ} 40^{\circ} 00^{\prime}$ '. The vegetation of Kano State is the semi-arid savannah. The Sudan Savannah is sandwiched by the Sahel Savannah in the north and the Guinea Savannah in the south. The savannah has been described as the zone that provides opportunity for optimal human attainment. This is because it is rich in faunal and floral resources, it is suitable for both cereal agriculture and livestock rearing, and the environment is relatively easy for movement of natural resources and manufactured goods. The figure 1 shows the study area.

\footnotetext{
* Corresponding author
} 


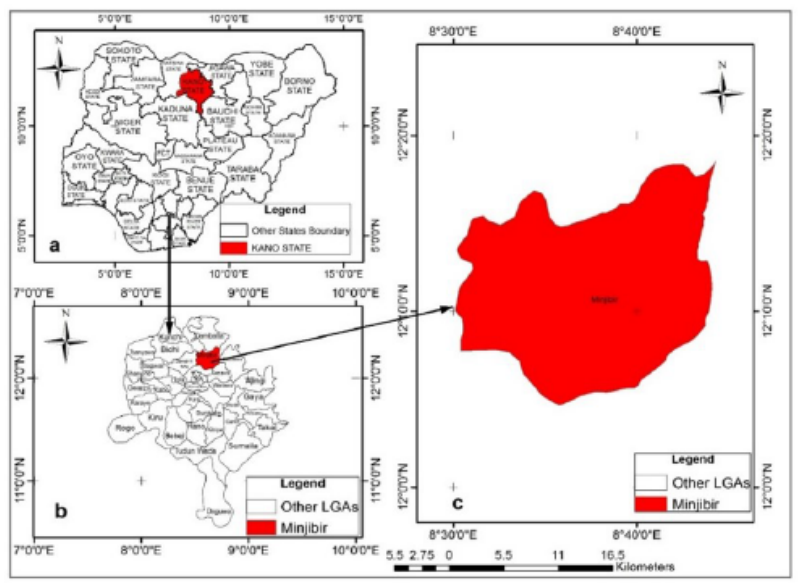

Figure 1: Study Area Map, a) Location of Kano State in Nigeria, b) Location of Minjibir LGA in Kano state, c) Minjibir LGA

\section{MATERIALS AND METHODS}

\subsection{Data Types and Sources}

Landsat 8 OLI and Sentinel 2A for three different years (2015, 2017 and 2019) were obtained. These images were used to generate the land use and land cover information, and vegetation indices (NDVI, GCI, LAI and, MSI) within the study area.

Atmospherically corrected surface reflectances of multispectral bands of Landsat 8 OLI were freely downloaded from the website of the United State Geological Survey (USGS) (see, http://earthexplorer.usgs.gov/ ). The Sentinels Scientific Data Hub website (see, https://scibub.copernicus. eu.dhus/) provided free download of the Sentinel 2A Levels$1 \mathrm{C}$ products. The downloaded images from Sentinel data hub images were atmospherically corrected by means of the European Space Agency's (ESA) Sen2Cor atmospheric correction toolbox that is an inherent procedure within the SentiNel Application Platform (SNAP) tool version 6.0 to supply the Level-2A (L2A) products.

The Table 1 contains the specifics about the assemblage of the cloud-free Sentinel-2A and Landsat 8 OLI images of the study area.

\begin{tabular}{|l|l|l|l|l|}
\hline S/no & $\begin{array}{l}\text { Date } \\
\text { acquired }\end{array}$ & Path/Row & $\begin{array}{l}\text { Cloud } \\
\text { Cover }\end{array}$ & $\begin{array}{l}\text { Date acquired } \\
\text { by Satellite }\end{array}$ \\
\hline Landsat8 OLI(30m resolution from USGS) \\
\hline 1 & 2015 & 188052 & $8.89 \%$ & $15^{\text {th June } 2015}$ \\
\hline 2 & 2017 & 188052 & $25.3 \%$ & $24^{\text {th }}$ June 2017 \\
\hline 3 & 2019 & 188052 & $9.5 \%$ & $21^{\text {st } J u n e ~ 2019 ~}$ \\
\hline Sentinel 2A (10m resolution from Copernicus) \\
\hline 4 & 2015 & N205 R79 & $0 \%$ & $27^{\text {th }}$ June 2015 \\
\hline 5 & 2017 & N205 R79 & $0 \%$ & $4^{\text {th June } 2017}$ \\
\hline 6 & 2019 & N205 R79 & $0 \%$ & $27^{\text {th }}$ June 2019 \\
\hline
\end{tabular}

Table1: Details of Landsat8 OLI and Sentinel 2A Image Acquisition

\subsection{Image Pre-processing}

The portion of interest (Minjibir LGA) was subsetted from each of the larger scenes using ArcGIS software. Geometric and radiometric corrections were performed on them for the purpose of ortho-rectification. The Sentinel 2A images were obtained at spatial resolution of $10 \mathrm{~m}$. Therefore, the Sentinel-2A images were up scaled to the same spatial resolution as the Landsat- 8 (i.e. $30 \mathrm{~m}$ ) to match the performances of the datasets of two satellites within the same spatial-scale. The two datasets were geo-referenced or geo-coded that is registered to a geographic frame of reference (UTM Zone 32).

During layer stacking, all bands of the sensor data excluding the thermal band were considered for Layers stacking. The nature of these different bands had to be considered to make a decision as to which three-band combination would be most helpful for classification and visual interpretation, thus the false colour composite was employed in this study.

\subsection{Image Classification and Accuracy Assessment}

A supervised classification was performed on false colour composites (bands 5, 4 and 3 for Landsat 8 OLI and bands 8, 4 and 3 for Sentinel 2A) into the following land use and land cover classes; Light vegetation Built-up area, Dense vegetation, Water body and Bare surfaces(see Table 2). The classification was done according to Anderson et al (1976). Information collected during the field surveys were combined with the digital satellite image, which was derived from SAS-planet software and used to assess the accuracy of the classification.

\begin{tabular}{lll}
\hline Code & $\begin{array}{l}\text { Land-use/Land } \\
\text { cover }\end{array}$ & Description \\
\hline 1 & Light vegetation & $\begin{array}{l}\text { Lands consisting of grassland, } \\
\text { cultivated area and plantation, } \\
2\end{array}$ \\
$\begin{array}{l}\text { Built-up land } \\
\text { industrial, commercial, etc. }\end{array}$ \\
3 & $\begin{array}{l}\text { Dense } \\
\text { vegetation }\end{array}$ & $\begin{array}{l}\text { Lands covered with natural } \\
\text { vegetation (any high tree } \\
\text { plant species) } \\
\text { Lands devoid of vegetation, } \\
\text { exposed soil } \\
\text { Land dominated by rivers, } \\
\text { lake and dams }\end{array}$ \\
\hline
\end{tabular}

Table 2: Classification Schemes

An accuracy assessment was done by determining a confusion matrix. This finds the relationships between the mapped class label and that observed on the ground or reference data for a sample of cases at specific locations. The overall accuracy can be determined by dividing the number of correctly classified pixels by the total number of reference pixels. Overall accuracy is considered as the most suitable method for calculating accuracy assessment. The Kappa coefficient of agreement was used to improve the overall accuracy.

\subsection{Estimating Vegetative Indices}

Landsat 8 OLI of 2015, 2017 and 2019 and Sentinel 2AMSI of 2015, 2017 and 2019 were used for estimating vegetative indices and subsequent analysis. Digital number was converted to spectral radiance for the Landsat 8OLI and then into reflectance. Different vegetative types have different spectral characteristics. Based on the understanding of the satellite spectral data, we obtained different spectral information 
regarding vegetation in the study area. Four (4) vegetative indices derived at all the satellite epochs as described in the succeeding subsection

\section{- Derivation of Moisture Stress Index(MSI)}

This index is sensitive to the increase of leaf water content. It is used for analyzing vegetation coverage, predicting the productivity and modeling, analyzing the plant use conditions and studying the ecosystem physiology. The MSI is calculated as a ratio of the mid-infrared (MIR) and the near-infrared (NIR)(Hunt et al., 1989; Welikhe et al., 2017). The formula used to derive the MSI is shown in equation (1).

$$
M S I=M I R / N I R
$$

- Derivation of Green Chlorophyll Index (GCL)

In remote sensing, the Green Chlorophyll Index is employed to estimate the content of leaf chlorophyll in countless species of plants. The chlorophyll content reveals the physiological condition of vegetation; it drops in strained plants and may therefore be used as a measurement of plant well-being. Enhanced estimation of chlorophyll amount with the GCI are often achieved by using satellite sensors that have broad NIR and green wavelengths (Gitelson et al., 2003). The formula used to derive the GCI is shown in equation (2).

$$
G C I=[(N I R) /(\text { Green })]-1
$$

\section{- Derivation of Normalized Difference Vegetation Index(NDVI)}

The NDVI is the most important vegetation index in remote sensing. It is widely used for analysing land use changes, including vegetation and other factors. This index is suitable for areas with moderate and higher vegetation density since it is less susceptible to soil and the effects of atmosphere.

The NDVI is calculated from the visible red and near infrared bands. The rationale of the index is that healthy vegetation has a high reflectance in the near infrared (NIR) and a low reflectance in the red, thereby enhancing the interpretation of vegetation cover while suppressing subtle noise from other land cover types(Rouse et al., 1974). The formula used to derive NDVI is shown in equation (3).

$$
N D V I=(r N I R-r R E D) /(r N I R+r R E D)
$$

Where $r$ is reflectance and is defined as in equation (4), in the equation (4), $L$ is spectral radiances at the sensor aperture, $d r$ is the inverse square of earth-sun distance, $E_{\text {sun }}$ represents the mean solar exoatmospheric irradiances, $\theta$ is the solar zenith angle and, $d$ is the distance from the earth to the sun.

$$
r=\frac{\pi * L * d^{2}}{E_{\text {sun }} * \operatorname{Cos} \theta * d r}
$$

\section{- Derivation of Leaf Area Index(LAI)}

LAI can be determined directly by taking a statistically significant sample of foliage from a plant canopy, measuring the leaf area per sample plot and dividing it by the plot land surface area. Indirect methods measure canopy geometry or light extinction and relate it to LAI (Juutinen et al., 2017). This study adopted a relation between the NDVI and LAI as presented in equation (5).

$$
L A I=22.758(N D V I)^{2}-13.107(N D V I)+2.197
$$

\section{RESULTS AND DISCUSSION}

\subsection{Detection of Land use and Land Cover Changes}

The total land area for Minijibir LGA is estimated to be $431.14 \mathrm{~km}^{2}$. The satellite data were classified using Maximum Likelihood Classification Algorithm of supervised classification into five types of land cover, including Built- up, Water body, dense vegetation, Light vegetation and bare land with the aid of ArcGIS software. In this classification, the rocks and uncultivated land that are not covered with vegetation are grouped under bare land while impervious surface are referred to as built-up.

The Landsat 8 and Sentinel 2A classified images for Minjibir LGA are illustrated in Appendix 1. The main aim of this classification is to access how Sentinel 2A behave over a high vegetation region as compared to Landsat 8 OLI.

The table 3 presents the area of each class extracted by different images. For Landsat 8, built-up areas cover 18.77, 20.14, and $22.59 \mathrm{~km}^{2}$ for 2015,2017 and 2019, respectively of the whole area, while for Sentinel 2A, built-up areas cover 14.34, 18.22, and $20.64 \mathrm{~km}^{2}$ for 2015,2017 and 2019 respectively of the whole area. This shows Sentinel 2A and Landsat 8 has extracted more hard surfaces areas (e.g. buildings, roads). However, Built up area dominated more in Landsat 8 as compared to Sentinel $2 \mathrm{~A}$ within the region. However, this may be because the built up signature for Sentinel 2A has better similar characteristics, and it is well clustered within similar wavelength bands.

\begin{tabular}{|l|r|r|r|}
\hline \multirow{2}{*}{ LULC } & \multicolumn{3}{|c|}{ Area $(\mathrm{km} 2)$} \\
\cline { 2 - 4 } & $\mathbf{2 0 1 5 ( S 2 A , ~ L 8 ) ~}$ & $\mathbf{2 0 1 7}(\mathbf{S 2 A}, \mathbf{L 8 )}$ & $\mathbf{2 0 1 9}(\mathbf{S 2 A}, \mathbf{L 8 )}$ \\
\hline $\begin{array}{l}\text { Light } \\
\text { vegetation }\end{array}$ & $201.15,201.74$ & $200.25,201.13$ & $202.12,206.14$ \\
\hline $\begin{array}{l}\text { Dense } \\
\text { vegetation }\end{array}$ & $110.46,116.53$ & $106.83,106.21$ & $99.03,95.62$ \\
\hline Bare land & $84.88,53.5$ & $82.18,83.54$ & $80.19,83.15$ \\
\hline Waterbody & $15.88,45.03$ & $21.74,22.04$ & $27.21,25.59$ \\
\hline Built up & $18.77,14.34$ & $20.14,18.22$ & $22.59,20.64$ \\
\hline Total & $431.14,431.14$ & $431.14,431.14$ & $431.14,431.14$ \\
\hline
\end{tabular}

$* * \mathrm{~S} 2 \mathrm{~A}=$ Sentinel2A, L8 = Landsat8 OLI

Table 3: Landsat-8 OLI and Sentinel 2A image classification

However, the major class differences in the area are observed in vegetation cover (Light and dense vegetation). Sentinel 2A extracted an area of $318.27 \mathrm{~km}^{2}, 307.34 \mathrm{~km}^{2}$ and $301.76 \mathrm{~km}^{2}$ for imagery of 2015, 2017 and 2019, respectively. In contrast, Landsat 8 OLI shows $311.61 \mathrm{~km}^{2}, 307.08 \mathrm{~km}^{2}$ and $301.15 \mathrm{~km}^{2}$ area for imagery of 2015, 2017 and 2019 respectively of the whole area covered with vegetation, thus, it can be argued that Landsat 8 and Sentinel $2 \mathrm{~A}$ has continuously classified vegetation accurately. Additionally, Sentinel 2A image showed $53.5 \mathrm{~km}^{2}, 83.54 \mathrm{~km}^{2}$ and $83.15 \mathrm{~km}^{2}$ area as bare cover for 2015 , 2017 and 2019 respectively, while for Landsat 8 bare cover is around $84.88 \mathrm{~km}^{2}, 82.18 \mathrm{~km}^{2}$ and $80.19 \mathrm{~km}^{2}$ for 2015,2017 and 2019 respectively. Finally, Sentinel $2 \mathrm{~A}$ has marked $45.03 \mathrm{~km}^{2}$, $22.04 \mathrm{~km}^{2}$ and $25.59 \mathrm{~km}^{2}$ for 2015,2017 and 2019 respectively of the area as water bodies. Landsat 8 has marked $15.88 \mathrm{~km}^{2}$, $21.74 \mathrm{~km}^{2}$ and $27.21 \mathrm{~km}^{2}$ as water bodies for 2015,2017 and 
2019 respectively. In contrast, signature developed for Sentinel $2 \mathrm{~A}$ on vegetation region are better fitted with water bodies and considered a good fit for vegetation areas when comparing the false colour composite (FCC). Features for Sentinel 2A are more related to specific objects, and they are clearly distinguishing the objects with clear boundaries but it usually misclassifies vegetation into water body within the project area. It is clear that even with optimized better resolution, Sentinel 2A water body signature for 2019 are not as well developed as Landsat 8 features.

\subsection{Image Classification Accuracy}

Accuracy analysis was undertaken using the confusion matrix otherwise referred to as the error matrix presented in Tables 4 . The confusion matrix involves different statistical measures such as producer's accuracy and user's accuracy for each of the classes, after which, the overall accuracy and kappa index for the classification were determined. The producer's accuracy was obtained by dividing the total number of pixels classified correctly in a category by the total number of pixels of that category as derived from the reference data. While the user accuracy, on the other hand, is expressed as the ratio of correctly classified pixels to the total number of pixels classified in that class. Hence, the result of the Landsat 8 (Table 4) shows that the producer's accuracy of light vegetation was $100 \%$, $98 \%, 96 \%$, for Sentinel 2A, against $93 \%, 89 \%$ and $100 \%$ for Landsat 8 for the three epoch period. With user accuracy of $98 \%, 100 \%, 100 \%$ against $85 \%, 97 \%$ and $89 \%$ for Landsat 8 for the three epoch period, bare land was $98 \%, 100 \%, 94 \%$, for Sentinel 2A, against $88 \%, 100 \%$ and $90 \%$ for Landsat 8 for the three epoch period. With user accuracy of $98 \%, 100 \%, 94 \%$ against $96 \%, 100 \%$ and $89 \%$ for Landsat 8 for the three epoch period, water body was $100 \%, 100 \%, 100 \%$, for Sentinel $2 \mathrm{~A}$, against $85 \%, 100 \%$ and $90 \%$ for Landsat 8 for the three epoch period. With user accuracy of $100 \%, 100 \%, 100 \%$ against $80 \%$, $84 \%$ and $100 \%$ for Landsat 8 for the three epoch period, and built-up was $96 \%, 94 \%, 100 \%$, for Sentinel 2 A, against $84 \%$, $79 \%$ and $88 \%$ for Landsat 8 for the three epoch period. With user accuracy of $98 \%, 98 \%, 100 \%$ against $84 \%, 100 \%$ and $85 \%$ for Landsat 8 for the three-epoch period. Finally, dense vegetation was $98 \%, 100 \%, 98 \%$, for Sentinel $2 \mathrm{~A}$, against $90 \%$, $98 \%$ and $85 \%$ for Landsat 8 for the three-epoch period. With user accuracy of $98 \%, 94 \%, 100 \%$ against $95 \%, 85 \%$ and $90 \%$ for Landsat 8 for the three-epoch period.

\begin{tabular}{|c|c|c|c|c|c|c|}
\hline \multirow[t]{2}{*}{$\begin{array}{l}\text { Land cover } \\
\text { Class }\end{array}$} & \multicolumn{2}{|c|}{$\begin{array}{c}2015 \\
\text { (S2A, L8) }\end{array}$} & \multicolumn{2}{|c|}{ 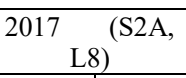 } & \multicolumn{2}{|c|}{$\begin{array}{c}2019 \\
\text { (S2A, L8) }\end{array}$} \\
\hline & $\begin{array}{l}\text { PA } \\
\text { (\%) }\end{array}$ & $\begin{array}{l}\text { UA } \\
(\%)\end{array}$ & $\begin{array}{l}\text { PA } \\
(\%)\end{array}$ & $\begin{array}{l}\text { UA } \\
(\%)\end{array}$ & $\begin{array}{l}\text { PA } \\
(\%)\end{array}$ & $\begin{array}{l}\text { UA } \\
(\%)\end{array}$ \\
\hline Water body & $\begin{array}{c}100 \\
85\end{array}$ & $\begin{array}{c}100 \\
80\end{array}$ & $\begin{array}{l}100 \\
100\end{array}$ & $\begin{array}{c}100 \\
84\end{array}$ & $\begin{array}{c}100 \\
90\end{array}$ & $\begin{array}{l}100 \\
100\end{array}$ \\
\hline $\begin{array}{l}\text { Dense } \\
\text { Vegetation }\end{array}$ & $\begin{array}{c}98 \\
90\end{array}$ & $\begin{array}{l}98 \\
95\end{array}$ & $\begin{array}{c}100 \\
98\end{array}$ & $\begin{array}{l}94 \\
85\end{array}$ & $\begin{array}{c}98 \\
85\end{array}$ & $\begin{array}{c}100 \\
90\end{array}$ \\
\hline $\begin{array}{l}\text { Built-up } \\
\text { Area }\end{array}$ & $\begin{array}{l}96, \\
84\end{array}$ & $\begin{array}{l}98 \\
84\end{array}$ & $\begin{array}{l}94 \\
79\end{array}$ & $\begin{array}{l}98, \\
100\end{array}$ & $\begin{array}{c}100 \\
88\end{array}$ & $\begin{array}{l}94 \\
85\end{array}$ \\
\hline Bare Land & $\begin{array}{l}98 \\
88 \\
\end{array}$ & $\begin{array}{l}98 \\
96 \\
\end{array}$ & $\begin{array}{l}100 \\
100 \\
\end{array}$ & $\begin{array}{l}100 \\
100 \\
\end{array}$ & $\begin{array}{l}94, \\
90 \\
\end{array}$ & $\begin{array}{l}94 \\
89 \\
\end{array}$ \\
\hline $\begin{array}{l}\text { Light } \\
\text { Vegetation }\end{array}$ & $\begin{array}{c}100 \\
93\end{array}$ & $\begin{array}{l}98 \\
85\end{array}$ & $\begin{array}{c}98 \\
89\end{array}$ & $\begin{array}{c}100 \\
97\end{array}$ & $\begin{array}{l}96 \\
100\end{array}$ & $\begin{array}{c}100 \\
89\end{array}$ \\
\hline $\begin{array}{l}\text { Overall } \\
\text { Accuracy }\end{array}$ & \multicolumn{2}{|c|}{$0.98,0.88$} & \multicolumn{2}{|c|}{$0.98,93.2$} & \multicolumn{2}{|c|}{$0.98,0.91$} \\
\hline $\begin{array}{l}\text { Kappa } \\
\text { Statistic }\end{array}$ & \multicolumn{2}{|c|}{$0.70,0.72$} & \multicolumn{2}{|c|}{$0.78,0.76$} & \multicolumn{2}{|c|}{$0.79,0.74$} \\
\hline
\end{tabular}

**PA = Producer's Accuracy, UA = User's Accuracy, S2A = Sentinel2A, L8 = Landsat8 OLI

Table 4: Classification Accuracy Assessment Report
The overall accuracy is the number of correctly classified pixels (sum of the diagonal cells) divided by the total number of pixels checked. The overall accuracy of Sentinel 2A was found to be $98 \%, 98 \%$ and $98 \%$ for the three-epoch period with a kappa index of $70 \%, 78 \%$, and $79 \%$ (Table 4). While the overall accuracy of Landsat 8 was found to be $88 \%, 93 \%$ and $91 \%$ for the three-epoch period with a kappa index of $72 \%, 76 \%$, and $74 \%$.In the accuracy assessment test results presented in Table 4 , it is quite clear that Sentinel 2A has better user accuracy and producer accuracy for built-up, water, bare land and vegetation classes compared to Landsat 8.

The overall accuracy of Sentinel 2A is considerably higher than Landsat 8 . However, the kappa for Sentinel $2 \mathrm{~A}$ is again higher than Landsat 8, apart from 2015 result, which records 0.70 of Sentinel 2A against 0.72 of Landsat 8 , despite being less than the standard acceptable threshold of 0.75 . The Landsat 8 kappa value is considerably lower for 2017 and 2019 imagery and indicates less credibility for Landsat 8 extractions in all the classes. The initial assumption of equal performance in some classes was no longer valid, and Sentinel 2A performed better than Landsat 8 with higher accuracy. Results show that Sentinel $2 \mathrm{~A}$ can be used in vegetation mapping with over $80 \%$ accuracy. In view of the value of the methods and the accessibility of Sentinel 2A, it might be considered an efficient substitute if progresses are made in terms of image processing and classification methods.

\subsection{Comparative Analysis of Landsat 8 OLI and Sentinel 2A Derived NDVI}

The NDVI value as presented in Table 5 revealed that lower NDVI is associated with the developed settlements while high NDVI values are associated with the less developed natural surfaces. The results of NDVI maps are shown in appendix 2 .

In Landsat 8 imagery, The highest values of the vegetation index were decreased from 0.51 in 2015 to 0.50 in 2017 and 0.49 in 2019 (Table 5). This shows that the vegetation cover was by far decreased in some parts of the area from 2015 to 2019. This can also be seen in (appendix2) as shades of green colour in both images. The darker the green colour in the image the highest NDVI values were recorded and the highest vegetation cover and vice versa. In the same way, the lowest values are decreased from -0.12 in 2015 to -0.11 in 2017 and 0.03 in 2019. This means that status of vegetation in 2015 is better than the vegetation in 2017 as the vegetation values tend to decrease. This comparison result shows that lowest vegetation cover was observed in 2015 whereas average vegetation cover was observed in 2017.

While in Sentinel 2A imagery, The highest values of the vegetation index were decreased from 0.8 in 2015 to 0.67 in 2017 and 0.67 in 2019 (Table 5). This shows that the vegetation cover was by far decreased in some parts of the area from 2015 to 2019. This can also be seen in (appendix 2) as shades of green colour in both images. The darker the green colour in the image the highest NDVI values were recorded and the highest vegetation cover and vice versa. In the same way, the lowest values are decreased from -0.3 in 2015 to -0.29 in 2017 and 0.17 in 2019. This means that status of vegetation in 2015 is better than the vegetation in 2017 as the vegetation values tend to decrease. This comparison result shows that lowest vegetation cover was observed in 2015 whereas the average vegetation cover was observed in 2017 as observed in Landsat 8 result. 


\begin{tabular}{lllllll}
\hline & \multicolumn{2}{l}{ Landsat 8 OLI } & \multicolumn{4}{c}{ Sentinel 2A } \\
\hline Year & $\begin{array}{l}\text { Lowest } \\
\text { Value }\end{array}$ & $\begin{array}{l}\text { Highest } \\
\text { Value }\end{array}$ & Mean & $\begin{array}{l}\text { Lowest } \\
\text { Value }\end{array}$ & $\begin{array}{l}\text { Highest } \\
\text { Value }\end{array}$ & Mean \\
\hline $\mathbf{2 0 1 5}$ & -0.12 & 0.51 & 0.21 & -0.3 & 0.8 & 0.20 \\
$\mathbf{2 0 1 7}$ & -0.11 & 0.5 & 0.17 & -0.29 & 0.67 & 0.23 \\
$\mathbf{2 0 1 9}$ & -0.03 & 0.49 & 0.21 & -0.17 & 0.67 & 0.22 \\
\hline \multicolumn{2}{l}{ Table 5 - NDVI Value Ranges for Landsat 8 and Sentinel 2A }
\end{tabular}

\subsection{Comparative Analysis of Landsat 8 OLI and Sentinel 2A Derived GCI}

The Green Chlorophyll Index is used to estimate the content of leaf chlorophyll in various species of plants. The chlorophyll content reflects the physiological state of vegetation; it decreases in stressed plants and can be used as a measurement of plant health. In Landsat 8 imagery, The highest values of the GCI were decreased from 1.65 in 2015 to 1.55 in 2017 and increased from 1.60 in 2019 (Table 6). This shows that the vegetation cover was decreased in some parts of the area from 2015 to 2017. This can also be seen in (Appendix 3). In the same way, the lowest values are decreased from -0.25 in 2015 to -0.21 in 2017 and -0.16 in 2019 . This means that status of vegetation in 2015 is better than the vegetation in 2017 as the vegetation values tend to decrease. This comparison result shows that lowest vegetation cover was observed in 2015 whereas average vegetation cover was observed in 2017.

While in Sentinel 2A imagery, the highest values of the GCI were decreased from 4.53 in 2015 to 2.77 in 2019 (Table 6). This shows that the vegetation cover was decreased in some parts of the area from 2015 to 2019. In the same way, the lowest values are decreased from --0.25 in 2015 to -0.25 in 2017 and 0.16 in 2019. This means that status of vegetation in 2015 is better than the vegetation in 2017 as the vegetation values tend to decrease. This comparison result shows that lowest vegetation cover was observed in 2015 where as average vegetation cover was observed in 2017 as observed in Landsat 8 result. The derived statistical results of the trend of GCI is presented in Table 6 .

\begin{tabular}{lllllll}
\hline & \multicolumn{2}{l}{ Landsat 8 OLI } & \multicolumn{4}{c}{ Sentinel 2A } \\
\hline Year & $\begin{array}{l}\text { Lowest } \\
\text { Value }\end{array}$ & $\begin{array}{l}\text { Highest } \\
\text { Value }\end{array}$ & Mean & $\begin{array}{l}\text { Lowest } \\
\text { Value }\end{array}$ & $\begin{array}{l}\text { Highest } \\
\text { Value }\end{array}$ & Mean \\
\hline $\mathbf{2 0 1 5}$ & -0.25 & 1.65 & 0.71 & -0.60 & 4.53 & 1.00 \\
$\mathbf{2 0 1 7}$ & -0.25 & 1.55 & 0.63 & -0.29 & 2.31 & 0.94 \\
$\mathbf{2 0 1 9}$ & -0.16 & 1.60 & 0.74 & -0.33 & 2.77 & 1.01 \\
\hline
\end{tabular}

Table 6: GSI Value Ranges for Landsat 8 and Sentinel 2A

\subsection{Comparative Analysis of Landsat 8 OLI and Sentinel 2A Derived MSI}

The values of MSI for Landsat 8 for 2015, 2017 and 2019 were observed with the range of values from 0.489 to $1.44,0.477$ to 2.152 and 0.517 to 1.847 respectively while 0.141 to $2.99,0.408$ to 2.656 and 0.330 to 3.502 respectively is derived from Sentinel 2A. It was observed that Sentinel 2A range of values continues to be greater than that of Landsat 8 (Appendix 4). Based on exploratory analysis, remote sensing measured MSI 2015, 2017 and 2019 mean value of 1.02, 1.08 and 1.04 was observed for Landsat 8 while $1.28,1.20$ and 1.23 was observed for Sentinel 2A respectively.

While in Sentinel 2A, the standard deviation of the MSI value shows that it ranges from 0.10 in 2015 to 0.12 in 2019 and
Landsat 8, the standard deviation of the MSI value shows that it ranges from 0.05 in 2015 to 0.06 in 2019 . Generally, the result of the MSI values shows that the vegetation cover values, in general, were reduced for Landsat 8 but increasing continuously for Sentinel 2A. A summary of the derived statistical results of the trend of MSI is presented in Table 7.

\begin{tabular}{lllllll}
\hline & \multicolumn{2}{l}{ Landsat 8 OLI } & \multicolumn{4}{c}{ Sentinel 2A } \\
\hline Year & $\begin{array}{l}\text { Lowest } \\
\text { Value }\end{array}$ & $\begin{array}{l}\text { Highest } \\
\text { Value }\end{array}$ & Mean & $\begin{array}{l}\text { Lowest } \\
\text { Value }\end{array}$ & $\begin{array}{l}\text { Highest } \\
\text { Value }\end{array}$ & Mean \\
\hline $\mathbf{2 0 1 5}$ & 0.49 & 1.44 & 1.03 & 0.14 & 2.99 & 1.28 \\
$\mathbf{2 0 1 7}$ & 0.47 & 2.15 & 1.08 & 0.41 & 2.66 & 1.20 \\
$\mathbf{2 0 1 9}$ & 0.52 & 1.85 & 1.04 & 0.33 & 3.50 & 1.23 \\
\hline
\end{tabular}

Table 7: MSI Value Ranges for Landsat 8 and Sentinel 2A

\subsection{Comparative Analysis of Landsat 8 OLI and Sentinel 2A Derived LAI}

High values of LAI for Landsat 8 for 2015, 2017 and 2019 were observed with the range of values from 0.31 to $4.03,0.31$ to 3.91 and 0.31 to 2.66 , respectively while 0.31 to $8.11,0.31$ to 4.00 and 0.31 to 5.00 respectively is derived from Sentinel 2A. It was observed that Sentinel 2Arange of values continue to be greater than that of Landsat 8 . Based on exploratory analysis, remote sensing measured LAI 2015, 2017 and 2019 mean value of $0.48,0.70$ and $0.50 \mathrm{~km}^{2}$ was observed for Sentinel 2A while $0.55,0.51$ and 0.53 were observed for Landsat 8 , respectively.

This comparison can be better explained by its mean and standard deviation of the three epoch's maps. The standard deviation of the LAI value for Landsat 8 shows the value ranges from 0.11 in 2015 to 0.1 in 2019 . While the standard deviation of the LAI value for Sentinel $2 \mathrm{~A}$ shows, the value ranges from 0.12 in 2015 to 0.2 in 2019. The Table 8 and Appendix 5 contain summary of the LAI as determined in the study area.

\begin{tabular}{lllllll}
\hline & \multicolumn{2}{l}{ Landsat 8 OLI } & \multicolumn{4}{c}{ Sentinel 2A } \\
\hline Year & $\begin{array}{l}\text { Lowest } \\
\text { Value }\end{array}$ & $\begin{array}{l}\text { Highest } \\
\text { Value }\end{array}$ & Mean & $\begin{array}{l}\text { Lowest } \\
\text { Value }\end{array}$ & $\begin{array}{l}\text { Highest } \\
\text { Value }\end{array}$ & Mean \\
\hline $\mathbf{2 0 1 5}$ & 0.31 & 4.03 & 0.48 & 0.31 & 8.11 & 0.56 \\
$\mathbf{2 0 1 7}$ & 0.31 & 3.91 & 0.67 & 0.31 & 4.00 & 0.52 \\
$\mathbf{2 0 1 9}$ & 0.31 & 2.66 & 0.48 & 0.31 & 4.99 & 0.53 \\
\hline
\end{tabular}

Table 8: LAI Value Ranges for Landsat 8 and Sentinel 2A

\subsection{Correlation Analysis of Landsat 8 OLI and Sentinel 2A Derived Vegetative Indices}

The Sentinel-2A MSI and Landsat-8 OLI spectral response functions are quite different. to look at the impact of this, scatterplots of simulated Sentinel 2A against simulated Landsat 8 OLI sensor reflectance were generated for every of the approximately equivalent sensor bands and for the derived vegetative index. The degree of correspondence between the sensor data was examined by reduced axis (RMA) regression that permits for both the dependent and independent variables to possess comparable error and implies that swapping the dependent and independent variables (i.e., the Sentinel-2A and Landsat- 8 band data) won't alter the bivariate relationship. The corresponding results of individual sensor (Sentinel 2Aand Landsat OLI) type was compared for the results generated from both pixel and index based classification using the coefficients of a linear regression and the Pearson correlation coefficient in other to identify whether they have a good linear correlation, or the regression lines depart slightly from the identity line. 
The relationship between the Sentinel $2 \mathrm{~A}$ and Landsat 8 is presented in Table 9. The figures 2-5 show the scatter plots for the different vegetation indices. It was observed from the Figures that there exists a weak correlation between Sentinel 2A and Landsat 8 . The cross-calibration analysis results showed that Coefficient of determinant values of the satellite data of Sentinel-2 and Landsat- 8 were obtained as $0.119,0.034$, and 0.590 for 2015, 2017 and 2019 respectively.

\begin{tabular}{|l|c|c|c|c|}
\hline \multirow{2}{*}{} & NDVI & GSI & MSI & LAI \\
\cline { 2 - 5 } & \multicolumn{3}{|c|}{ Coefficient of Determination( $\left.\mathbf{R}^{\mathbf{2}}\right)$} \\
\hline 2015 & 0.119 & 0.263 & 0.452 & 0.072 \\
\hline 2017 & 0.034 & 0.154 & 0.382 & 0.032 \\
\hline 2019 & 0.590 & 0.520 & 0.598 & 0.237 \\
\hline \multicolumn{4}{|c|}{ Correlation Coefficient (r) } \\
\hline 2015 & 0.345 & 0.513 & 0.672 & 0.269 \\
\hline 2017 & 0.184 & 0.392 & 0.618 & 0.179 \\
\hline 2019 & 0.770 & 0.721 & 0.773 & 0.487 \\
\hline
\end{tabular}

Table 9: Coefficient of Determination $\left(\mathrm{R}^{2}\right)$ and Correlation Coefficient(r) Values for Landsat8 and Sentinel 2A

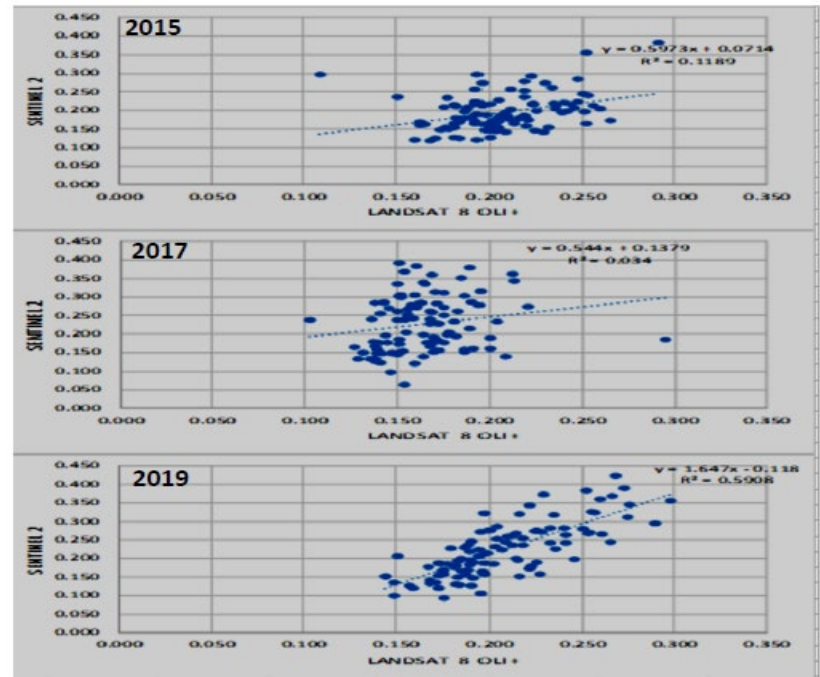

Figure 2: Scatter Plots for NDVI Relationship in Landsat 8 OLI and Sentinel 2A

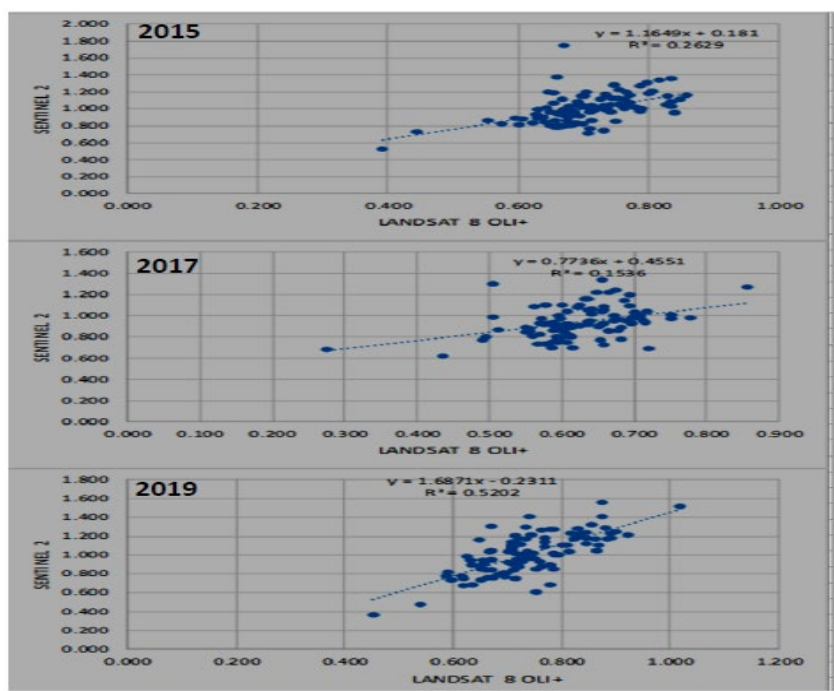

Figure 3: Scatter Plots for GCI Relationship in Landsat 8 OLI and Sentinel 2A

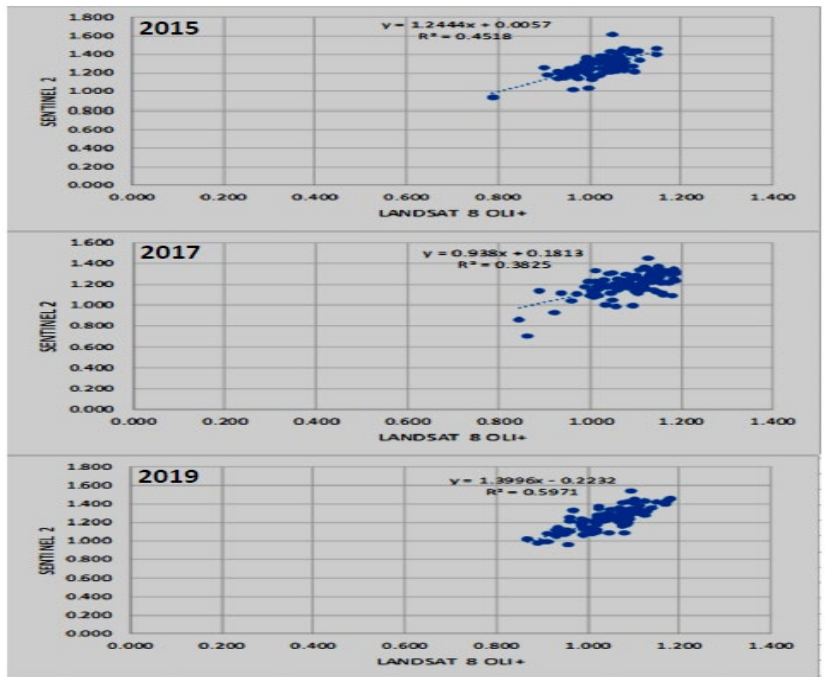

Figure 4: Scatter Plots for MSI Relationship in Landsat 8 OLI and Sentinel 2A

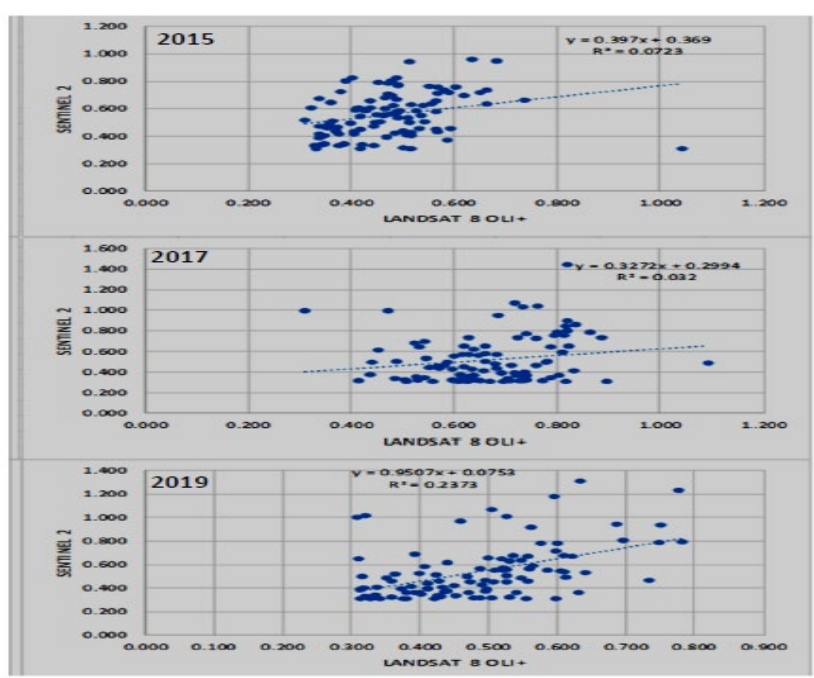

Figure 2: Scatter Plots for LAI Relationship in Landsat 8 OLI and Sentinel 2A

\section{CONCLUSION}

In this study, the multi-temporal analysis was performed on two different satellite sensor (Sentinel 2Aand Landsat 8 OLI for Minjibir LGA of Kano State. Through the retrieved vegetation indices, it was observed that high vegetation indices are attributed with Sentinel 2Avalue with respect to Landsat 8 throughout the time of study. From the comparison, it was found that the supervised classification from both the two sources are corresponding. Correlation was also made between the NDVI, MSI, GCI and LAI of the Landsat 8 and Sentinel 2A data. The result of correlation between Landsat 8 and Sentinel $2 \mathrm{~A}$ for the indices shows that the two are weakly correlated. However, the best average performance over the supervised classification was obtained using Sentinel-2 bands. The models based on Sentinel-2 data outperformed Landsat 8 models for all forest variables. Results were clearly shown in Sentinel 2A supervised classification due to the fine spatial resolution of 10 $\mathrm{m}$. The study recommends the integration of datasets from satellite remoting sensing sensors for improved or optimized vegetation monitoring. 


\section{REFERENCES}

Anderson, J.R., Hardy, E.E., Roach, J.T., Witmer, R.E, 1976: A land use and land cover classification system for use with remote sensor data. US. Geological Survey professional paper964, doi.org/10.3133/pp964.

Gitelson, A.A., Vina, A., Arkebauer, T. J., Rundquist, D. C., Keylan, G., Leavitt, B., 2003: Remote Estimation of Leaf Area Index and Green Leaf Biomas in Maize Canopies. Geophysical Research Letters, 30, 1248, doi: 10.1029/2002GL01650.

Hunt Jr, E.R., Rock, B.N., 1989: Detection of Changes in Leaf Water Content using near-and Middle-Infrared Reflectance. Remote Sens. Environ 30:43-54.

Intergovernmental Panel on Climate Change (IPCC). Climate Change 2014: Synthesis Report. Contribution of Working Groups I, II and III to the Fifth Assessment Report of the Intergovernmental Panel on Climate Change; IPCC: Geneva, Switzerland, 2014; p. 151.

Juutinen, S., Virtanen, T., Kondratyev, V., Laurila, T., Linkosalmi, M., Mikola, J., et al., 2017: Spatial Variation and
Seasonal Dynamics of Leaf-Area Index in the Arctic TundraImplications for Linking Ground Observations and Satellite Images. Environmental Research Letters, 12(19), 095002.

Melaas, E.K., Melaas, M.A., Friedl, Z. Z., 2013: Detecting interannual variation in deciduous broadleaf forest phenology using Landsat TM/ETM plus data. Remote Sens. Environ., 132 pp. 176-185.

Rouse, J.W., Haas, R.H., Schell, J.A., Deering, D.W., 1974: Monitoring Vegetation Systems in the Great Plains with ERTS. Third ERTS-1 Symposium, 309-317. Washington, DC: NASA. Welikhe, P., Quensch, J.E., Falls, S., Elhemey, W. Mc., 2017: Estimation of Soil Moisture Percentage Using LANDSAT based Moisture Stress Index. J. Remote Sensing \&GIS 6:200: doi 10.4172/2469-4134.1000200.

Yuanhuizi He., Changlin W., Fang C., Huicong J., Dong L., Aqiang Y., 2019: Feature Comparison and Optimization for 30M Winter Wheat Mapping Based on Landsat-8 and Sentinel-2 Data Using Random Forest. Algorithm. 170, 39-50.

\section{APPENDIX}
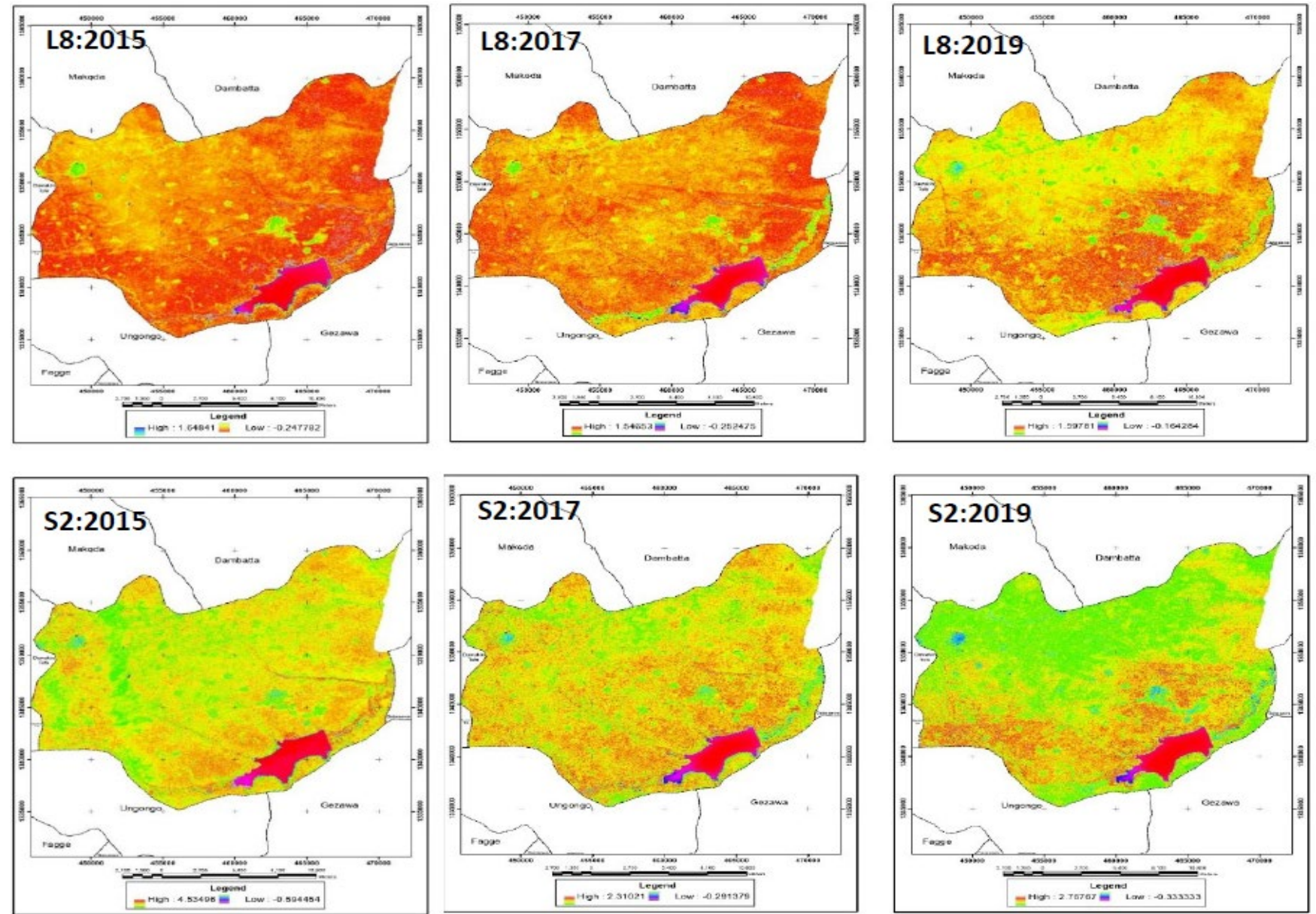

Appendix 1: Landsat-8 (L8) and Sentinel 2A (S2) image classification for 2015-2019 


\section{APPENDIX}
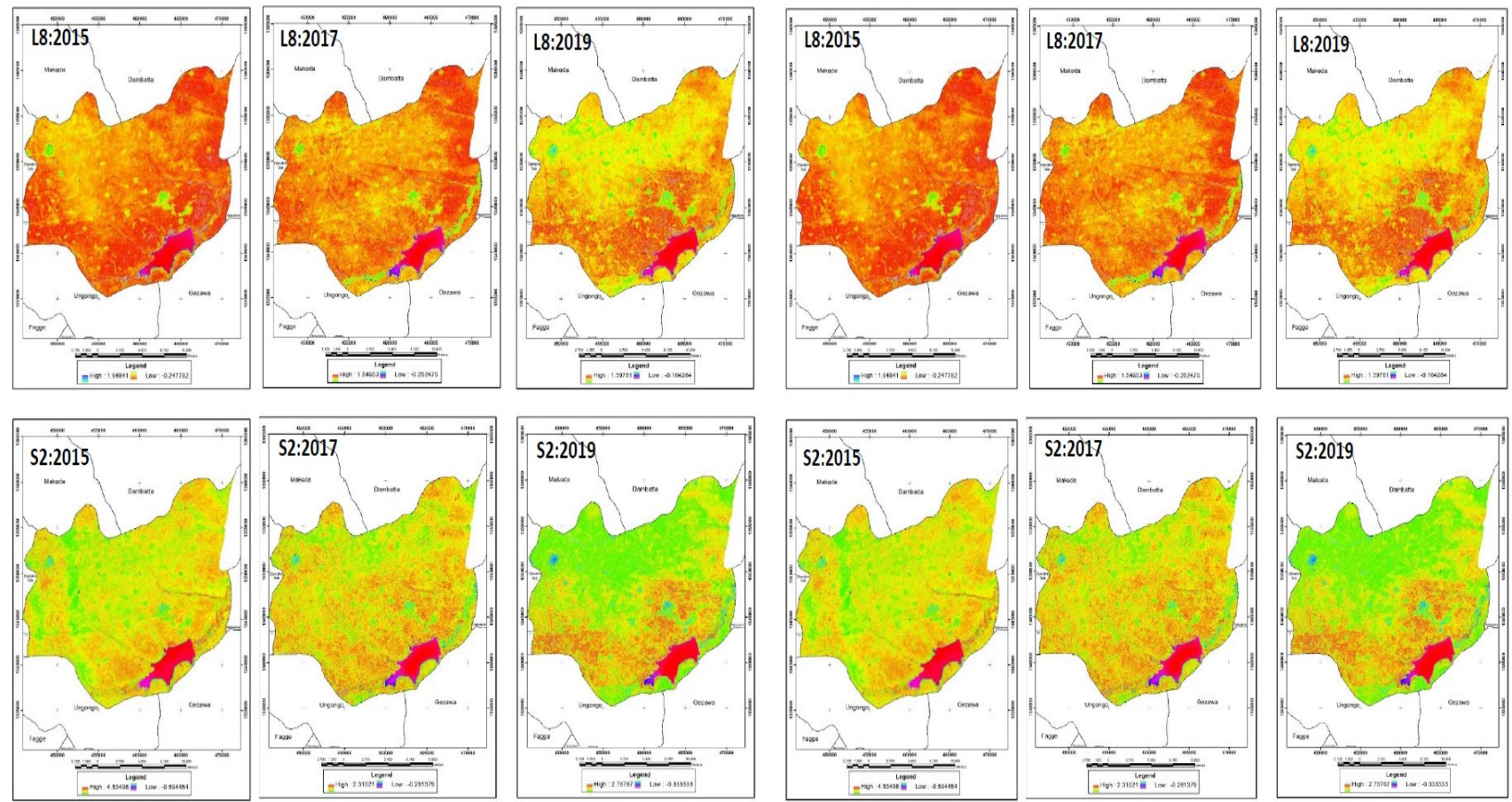

Appendix 2: Landsat-8 (L8) and Sentinel 2A (S2) Derived NDVI for 2015-2019

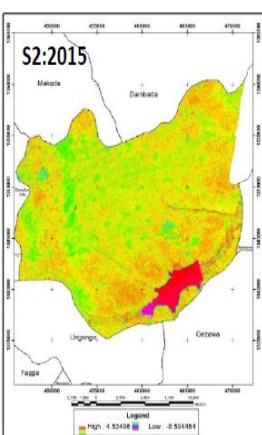

Appendix 4: Landsat-8
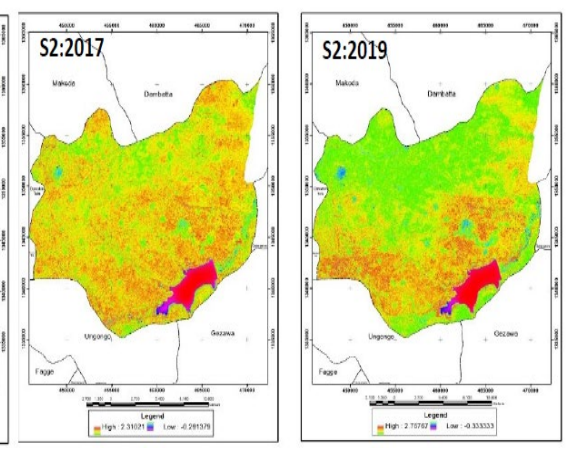
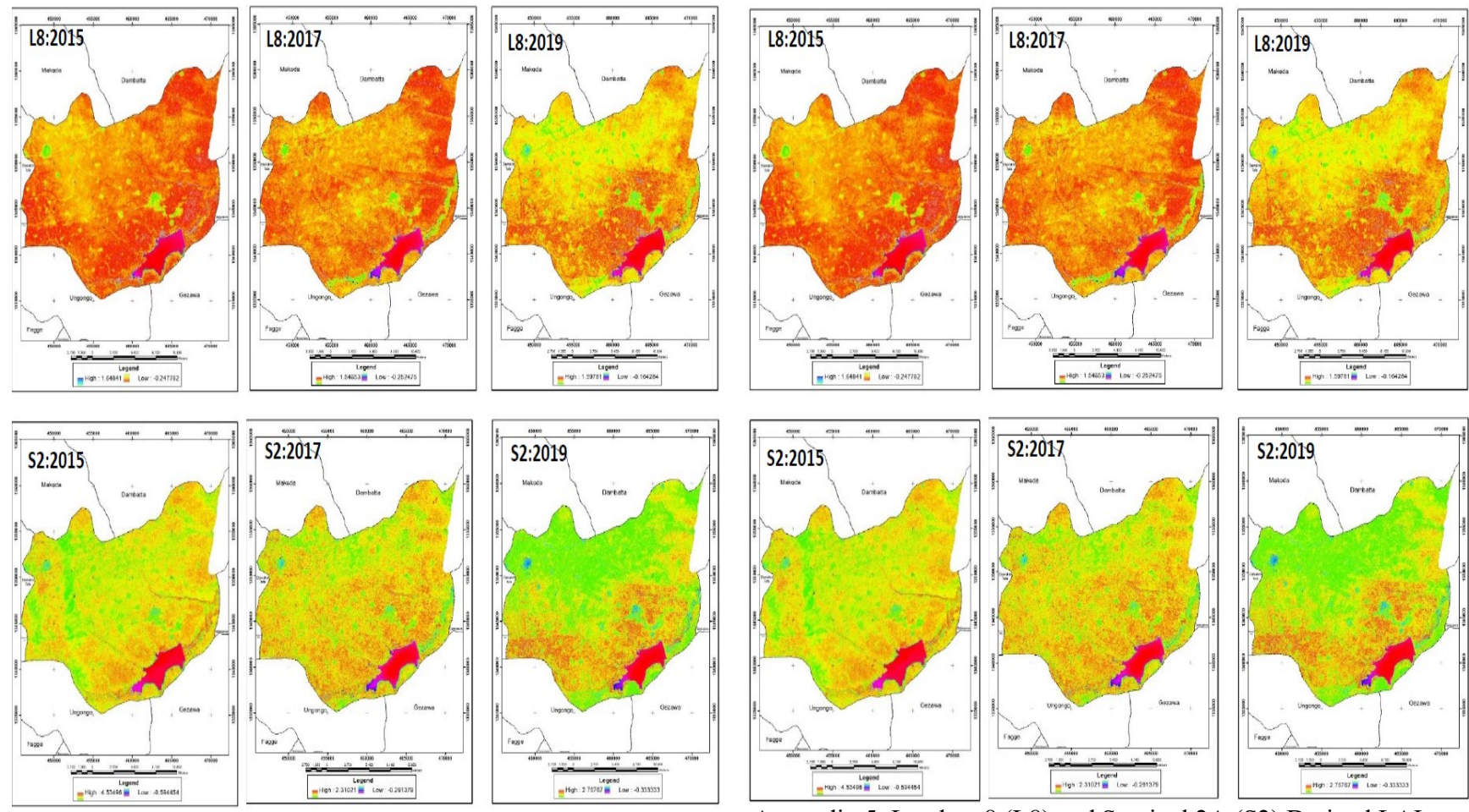

Appendix 3: Landsat-8 (L8) and Sentinel 2A (S2) Derived GSI for 2015-2019

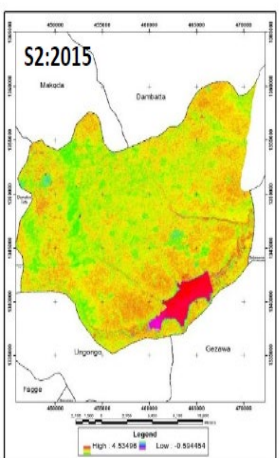

Appendix 5: Landsat-8
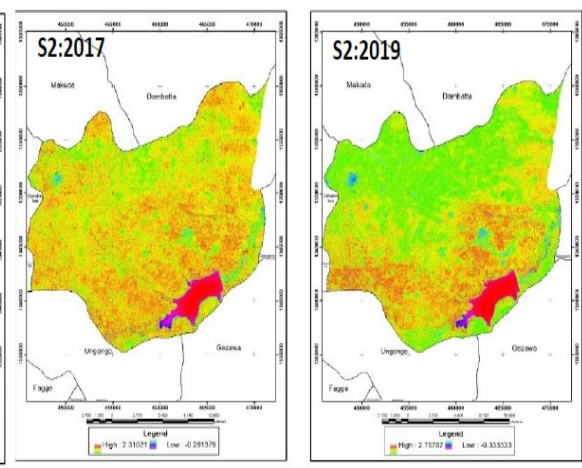

8) and Sentinel 2A (S2) Derived LAI for 2015-2019 